\title{
Pulmonary Embolism Severity Index and Simplified Pulmonary Embolism Severity Index Risk Scores Are Useful to Predict Mortality in Japanese Patients With Pulmonary Embolism
}

Atsushi Mizuno, MD; Takeshi Yamamoto, MD; Yasuhiro Tanabe, MD; Toru Obayashi, MD; Morimasa Takayama, MD; Ken Nagao, MD, PhD; Tokyo CCU Network Scientific Committee

\begin{abstract}
Background: The Pulmonary Embolism Severity Index (PESI) and simplified PESI (sPESI) have not been fully evaluated in Japan, so the present study aimed to evaluate these risk stratification models in the prediction of mortality of affected patients in Japan.

Methods and Results: We retrospectively analysed 302 PE patients (63.9 \pm 17.2 years of age; $42.4 \%$ male) from January 2011 to December 2012 using data from the Tokyo CCU Network. The areas under the receiver-operating characteristic curves were 0.92 (95\% confidence interval $(\mathrm{Cl}): 0.88-0.97)$ for the PESI and $0.88(95 \% \mathrm{Cl}: 0.77-0.98)$ for the SPESI.
\end{abstract}

Conclusions: Both scores can be used to predict PE mortality in Japan. (Circ J 2015; 79: 889-891)

Key Words: Length of stay; PESI score; Pulmonary embolism; Risk stratification

$\mathbf{T}$ he pulmonary embolism severity index (PESI) and the simplified PESI (sPESI) are both well-validated and highly reliable clinical prognostic markers for patients with acute pulmonary embolism (PE). ${ }^{1-3}$ Although using these risk stratification models has been advocated in the guidelines of other countries, neither has been fully evaluated in Japan. ${ }^{4}$ Our aim in the present study was to evaluate their ability to predict 30-day mortality in Japanese PE patients.

\section{Methods}

The study was performed using data from the Tokyo CCU Network. This network is operated by 67 hospitals with the help of ambulance units through the control room of the Tokyo Fire Department. Institutions belonging to the Tokyo CCU Network routinely record and submit details on survey forms of all patients treated in their cardiovascular care units (CCUs). ${ }^{5-7}$ In this study, subjects comprised a continuous series of $485 \mathrm{PE}$ cases treated at the institutions belonging to the Tokyo CCU Network between January 2011 and December 2012 (30-day mortality rate was $6.2 \%$ ). Any subjects with missing data required to calculate either the PESI or SPESI score were excluded. The original PESI consists of 11 predictors: 2 demographic variables (age and male sex), 3 comorbid conditions (cancer, heart failure and chronic lung disease), and 6 clinical factors (pulse rate $\geq 110$ beats $/ \mathrm{min}$, systolic blood pressure $<100 \mathrm{mmHg}$, respiratory rate $>30$ breaths $/ \mathrm{min}$, temperature $<36^{\circ} \mathrm{C}$, arterial oxygen saturation $<90 \%$ and altered mental status). The sPESI includes only 6 variables (age $>80$ years, history of cancer, chronic cardiopulmonary disease, pulse rate $\geq 110$ beats $/ \mathrm{min}$, systolic blood pressure $<100 \mathrm{mmHg}$ and arterial oxyhemoglobin saturation $<90 \%$ ) of equal weight (1 point per variable). ${ }^{8,9}$

\section{Results}

We retrospectively analysed $302(62.3 \%)$ patients (age $63.9 \pm 17.2$ years; $42.4 \%$ male). PESI and sPESI risk classification distributions and mortality prediction are shown in Table A. The length of stay was not significantly different between each class (Table B). Receiver-operating characteristic (ROC) curves for mortality are shown in the Figure. The areas under the ROC curves were 0.92 (95\% confidence interval [CI]: 0.88-0.97) for the original PESI score and 0.88 (95\% CI: 0.77-0.98) for the sPESI score. There were no significant differences in prediction of mortality between the scores $(\mathrm{P}=0.383)$.

Received January 5, 2015; revised manuscript received February 10, 2015; accepted February 11, 2015; released online February 26, 2015 Time for primary review: 23 days

Tokyo CCU Network Scientific Committee, Tokyo (A.M., T.Y., Y.T., T.O., M.T., K.N.); Department of Cardiology, St. Luke's International Hospital, Tokyo (A.M.), Japan

Mailing address: Atsushi Mizuno, MD, Department of Cardiology, St. Luke's International Hospital, 9-1 Akashi-cho, Chuo-ku, Tokyo 104-8560, Japan. E-mail: atmizu@luke.ac.jp

ISSN-1346-9843 doi:10.1253/circj.CJ-14-1433

All rights are reserved to the Japanese Circulation Society. For permissions, please e-mail: cj@j-circ.or.jp 
Table. (A) Patient Variables for Calculating PESI and SPESI, (B) Risk Classification and Outcomes for the Original and SPESI Scores

\begin{tabular}{|c|c|c|c|}
\hline (A) Variable & $\begin{array}{l}\text { Total patients } \\
\quad(n=302)\end{array}$ & $\begin{array}{l}\text { Included in } \\
\text { sPESI }\end{array}$ & \\
\hline Age & $63.9 \pm 17.2$ & & \\
\hline Age $>80$ years (for sPESI only), $n(\%)$ & $64(21.2)$ & J & \\
\hline Male sex, $\mathrm{n}(\%)$ & $127(42.1)$ & & \\
\hline Cancer, n (\%) & $11(3.6)$ & $\sqrt{ }$ & \\
\hline Chronic heart failure, $\mathrm{n}(\%)$ & $10(3.3)$ & $\sqrt{ }$ & \\
\hline Chronic pulmonary disease, $\mathrm{n}(\%)$ & $9(3.0)$ & & \\
\hline Pulse rate $\geq 110$ beats/min, $n(\%)$ & 85 (28.1) & & \\
\hline Systolic blood pressure $<100 \mathrm{mmHg}, \mathrm{n}(\%)$ & $51(16.9)$ & $\sqrt{ }$ & \\
\hline Respiratory rate $>30$ breaths/min, $\mathrm{n}(\%)$ & $37(12.3)$ & $\sqrt{ }$ & \\
\hline Temperature $<36^{\circ} \mathrm{C}, \mathrm{n}(\%)$ & $49(16.2)$ & & \\
\hline Altered mental status, n (\%) & $30(9.9)$ & & \\
\hline Arterial oxyhemoglobin saturation $<90 \%, \mathrm{n}(\%)$ & $57(18.9)$ & $\sqrt{ }$ & \\
\hline (B) Risk-class distribution & $\begin{array}{c}\text { No. of patients, } \mathbf{n} \\
(\%)\end{array}$ & $\begin{array}{l}\text { Mortality, } \mathrm{n} \\
(\%)\end{array}$ & $\begin{array}{l}\text { Length of stay, } \\
\text { days }\end{array}$ \\
\hline \multicolumn{4}{|l|}{ PESI } \\
\hline Class I: $\leq 65$ points & $68(22.5)$ & $0(0)$ & $17.4 \pm 9.4$ \\
\hline Class II: $66-85$ points & $81(26.8)$ & $0(0)$ & $18.6 \pm 13.3$ \\
\hline Class III: $86-105$ points & $59(19.5)$ & $0(0)$ & $19.8 \pm 18.4$ \\
\hline Class IV: $106-125$ points & $27(8.9)$ & $0(0)$ & $25.7 \pm 24.3$ \\
\hline Class V: $>125$ points & $67(22.2)$ & $7(10.4)$ & $22.2 \pm 17.1$ \\
\hline \multicolumn{4}{|l|}{ sPESI } \\
\hline Low risk: 0 points & $122(40.4)$ & $0(0)$ & $18.2 \pm 15.1$ \\
\hline High risk: $\geq 1$ point(s) & $180(59.6)$ & $7(3.9)$ & $21.1 \pm 16.3$ \\
\hline
\end{tabular}

PESI, pulmonary embolism severity index; sPESI, simplified PESI.

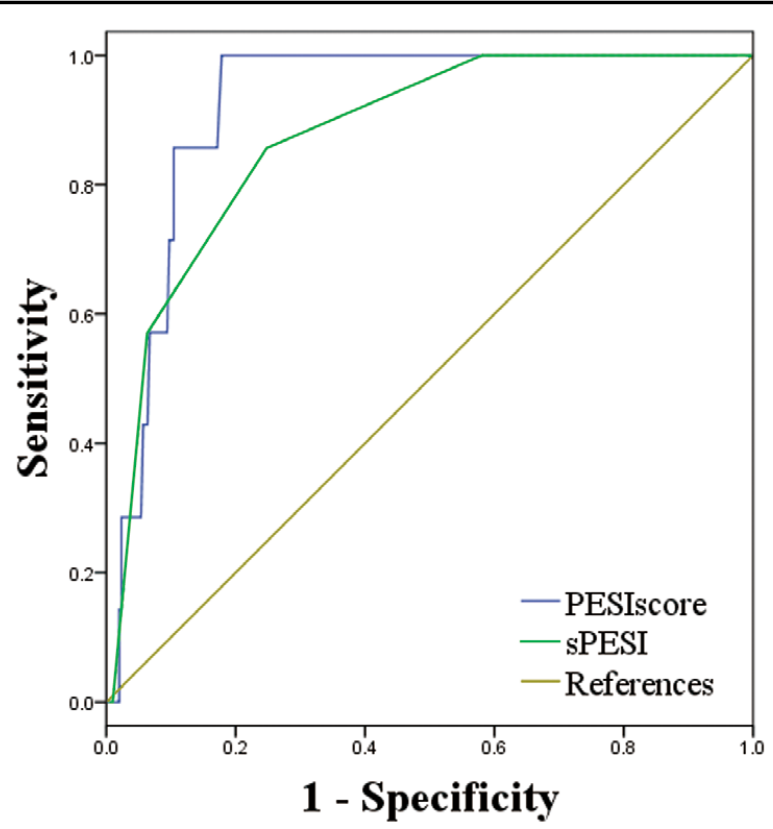

Figure. Receiver-operating characteristic (ROC) curves for mortality. The areas under the ROC curves were $0.92(95 \%$ confidence interval $[\mathrm{Cl}]$ : 0.88-0.97) for the original pulmonary embolism severity index (PESI) score and $0.88(95 \% \mathrm{Cl}$ : $0.77-0.98$ ) for the simplified PESI (sPESI) score. There were no significant differences in prediction of mortality between the PESI and SPESI scores $(P=0.383)$.

\section{Discussion}

Our study has 2 important clinical implications. First, we can report the usefulness of risk models to predict mortality in Japanese PE patients, and that there were no significant differences between the 2 models. Either can be used to predict mortality. Second, the length of stay was the same for each class. A recent European Society of Cardiology guideline has advocated that low-risk patients could be considered for early discharge and home treatment. Our registry data showed that there were no significant differences in length of stay between each risk category. Recently, new oral anticoagulation drugs, without the necessity of titration, were approved in Japan. We might be able to consider early discharge of low-risk patients with these new drugs. ${ }^{10,11}$ Further investigations are needed to assess the appropriateness of these risk stratification models, which could be used to determine the length of stay in Japan.

\section{Study Limitations}

Our data showed a quite low mortality rate (2.5\%), compared with previous studies. We could use only data from patients with the variables required to estimate the PESI score, which resulted in the selection of relatively lower-risk patients (total mortality rate was $6.2 \%$ for all consecutive PE patients from the Tokyo CCU Network database). Furthermore, the CCU Network database had a relatively low frequency of cancer/ lung disease patients and a high frequency of low-oxygenation patients. These differences in patient characteristics might result in a relatively lower mortality rate. But we could successfully confirm that the scores were useful to predict the mortality of PE patients, especially in the low-risk population. 
Further evaluation of more appropriate prediction models for Japanese PE patients and determining their length of stay are needed.

\section{Conclusions}

Both the PESI and sPESI risk scores could be used to predict 30-day mortality in Japanese patients with PE.

\section{Disclosures}

Funding: No conflicts of interest exist in this study.

\section{References}

1. Aujesky D, Roy PM, Le Manach CP, Verschuren F, Meyer G, Obrosky DS, et al. Validation of a model to predict adverse outcomes in patients with pulmonary embolism. Eur Heart J 2006; 27: $476-481$.

2. Righini M, Roy PM, Meyer G, Verschuren F, Aujesky D, Le Gal G. The simplified pulmonary embolism severity index (PESI): Validation of a clinical prognostic model for pulmonary embolism. $J$ Thromb Haemost 2011; 9: 2115-2117.

3. Venetz C, Jimenez D, Mean M, Aujesky D. A comparison of the original and simplified pulmonary embolism severity index. Thromb Haemost 2011; 106: 423-428.

4. Konstantinides SV, Torbicki A, Agnelli G, Danchin N, Fitzmaurice
D, Galie N, et al. 2014 ESC Guidelines on the Diagnosis and Management of Acute Pulmonary Embolism: The Task Force for the Diagnosis and Management of Acute Pulmonary Embolism of the European Society of Cardiology (ESC) endorsed by the European Respiratory Society (ERS). Eur Heart J 2014; 35: 3033-3073.

5. Tokyo CCU Network Scientific Committee. Latest management and outcomes of major pulmonary embolism in the cardiovascular disease early transport system: Tokyo CCU Network. Circ J 2010; 74: 289-293.

6. Tanabe Y, Obayashi T, Yamamoto T, Nakata J, Yagi H, Takayama $\mathrm{M}$, et al. Current status of the use of inferior vena cava filters in cases of pulmonary embolism in CCUS: From the Tokyo CCU Network. J Cardiol 2014; 63: 385-389.

7. Akutsu K, Yoshino H, Tobaru T, Hagiya K, Watanabe Y, Tanaka K, et al. Acute type B aortic dissection with communicating vs. noncommunicating false lumen: Analysis of 502 patients from the Tokyo CCU-Network database. Circ J 2015; 79: 567-573.

8. Aujesky D, Obrosky DS, Stone RA, Auble TE, Perrier A, Cornuz J, et al. A prediction rule to identify low-risk patients with pulmonary embolism. Arch Intern Med 2006; 166: 169-175.

9. Jimenez D, Aujesky D, Moores L, Gomez V, Lobo JL, Uresandi F, et al. Simplification of the pulmonary embolism severity index for prognostication in patients with acute symptomatic pulmonary embolism. Arch Intern Med 2010; 170: 1383-1389.

10. Antman EM. Clinical research and the development of medical therapeutics. Circ J 2014; 78: 1267-1271.

11. Yasaka M, Lip GY. Impact of non-vitamin K antagonist oral anticoagulants on intracranial bleeding in Asian patients with non-valvular atrial fibrillation. Circ J 2014; 78: 2367-2372. 